\title{
Antiproliferative and Antitumour Effect of Nongenotoxic Silver Nanoparticles on Melanoma Models
}

\author{
Lucía M. Valenzuela-Salas, ${ }^{1}$ Nayeli G. Girón-Vázquez, ${ }^{2}$ Juan C. García-Ramos, ${ }^{3}$ \\ Olivia Torres-Bugarín, ${ }^{4}$ Claudia Gómez, ${ }^{2}$ Alexey Pestryakov, ${ }^{5}$ Luis J. Villarreal-Gómez $\mathbb{D},{ }^{6}$ \\ Yanis Toledano-Magaña $\mathbb{D}^{3}{ }^{3}$ and Nina Bogdanchikova ${ }^{7}$ \\ ${ }^{1}$ Escuela de Ciencias de la Salud, Universidad Autónoma de Baja California, Tijuana, Baja California, Mexico \\ ${ }^{2}$ Facultad de Ingeniería, Arquitectura y Diseño, Universidad Autónoma de Baja California, Ensenada, Baja California, Mexico \\ ${ }^{3}$ Departamento de Fisicoquímica de Nanomateriales, CONACyT-UNAM-CNyN, Ensenada, Baja California, Mexico \\ ${ }^{4}$ Programa Internacional de Medicina, Universidad Autónoma de Guadalajara, Zapopan, Jalisco, Mexico \\ ${ }^{5}$ Department of Technology of Organic Substances and Polymer Materials, Tomsk Polytechnic University, Tomsk, Russia \\ ${ }^{6}$ Escuela de Ciencias de la Ingeniería y Tecnología, Universidad Autónoma de Baja California, Tijuana, Baja California, Mexico \\ ${ }^{7}$ Departamento de Fisicoquímica de Nanomateriales, Centro de Nanociencias y Nanotecnología, Universidad Nacional Autónoma \\ de México, Ensenada, Baja California, Mexico
}

Correspondence should be addressed to Yanis Toledano-Magaña; yanistoledano@cnyn.unam.mx

Received 12 February 2019; Revised 25 April 2019; Accepted 29 May 2019; Published 25 July 2019

Guest Editor: Nagendra K. Kaushik

Copyright @ 2019 Lucía M. Valenzuela-Salas et al. This is an open access article distributed under the Creative Commons Attribution License, which permits unrestricted use, distribution, and reproduction in any medium, provided the original work is properly cited.

\begin{abstract}
During the last 3 decades, there has been a slow advance to obtain new treatments for malignant melanoma that improve patient survival. In this work, we present a systematic study focused on the antiproliferative and antitumour effect of AgNPs. These nanoparticles are fully characterized, are coated with polyvinylpyrrolidone (PVP), and have an average size of $35 \pm 15 \mathrm{~nm}$ and a metallic silver content of $1.2 \% \mathrm{wt}$. Main changes on cell viability, induction of apoptosis and necrosis, and ROS generation were found on B16-F10 cells after six hours of exposure to AgNPs $\left(\mathrm{IC}_{50}=4.2 \mu \mathrm{g} / \mathrm{mL}\right)$ or Cisplatin $\left(\mathrm{IC}_{50}=2.0 \mu \mathrm{g} / \mathrm{mL}\right)$. Despite the similar response for both AgNPs and Cisplatin on antiproliferative potency (cellular viability of $53.95 \pm 1.88$ and $53.62 \pm 1.04$ ) and ROS production $(20.27 \pm 1.09 \%$ and $19.50 \pm 0.35 \%)$, significantly different cell death pathways were triggered. While AgNPs induce only apoptosis $(45.98 \pm 1.88 \%)$, Cisplatin induces apoptosis and necrosis at the same rate $(22.31 \pm 1.72 \%$ and $24.07 \pm 1.10 \%$, respectively). In addition to their antiproliferative activity, in vivo experiments showed that treatments of 3, 6 , and $12 \mathrm{mg} / \mathrm{kg}$ of AgNPs elicit a survival rate almost 4 times higher $(P<0.05)$ compared with the survival rate obtained with Cisplatin $(2 \mathrm{mg} / \mathrm{kg})$. Furthermore, the survivor mice treated with AgNPs do not show genotoxic damage determined by micronuclei frequency quantification on peripheral blood cells. These results exhibit the remarkable antitumour activity of a nongenotoxic AgNP formulation and constitute the first advance toward the application of these AgNPs for melanoma treatment, which could considerably reduce adverse effects provoked by currently applied chemotherapeutics.
\end{abstract}

\section{Introduction}

Melanoma is the most aggressive form of skin cancer and one of the deadliest. The morbidity and mortality of melanoma have increased in recent decades around the world with more than 100,000 new cases reported every year, and the incidence increase continues [1]. The incidence in fair-skinned populations always has the highest growth rates [2], but recently a $500 \%$ increase in new cases in Mexico has been reported [3].

In the last 3 decades, there have not been new treatments that efficiently improve patient survival [4]. Melanoma treatment faces two important problems: the adverse effects of chemotherapy due to the lack of selectivity and the low 
efficiency of the used methods [5]. Even with the resistance and severe adverse effects observed, Cisplatin (CisPt) continues to be the most used drug [6].

In the last decade, inorganic nanoparticles have attracted the interest of several research groups due to their applications in cancer therapy, either as drug nanocarriers or as therapeutic agents $[7,8]$. Particularly for the second purpose, silver nanoparticles (AgNPs) have been widely studied. However, their physicochemical properties play a key role in both facets, to fight cancer and to cause adverse effects [9].

In this sense, the employment of polyvinylpyrrolidone (PVP) as a coating agent of AgNPs produces an important decrease in cytotoxic and genotoxic effects compared with noncoated or citrate-AgNPs [10-12]. The PVP-AgNPs could also provide several advantages through selectivity in their antiproliferative action. The commercial formulation of PVP-AgNPs from Skyspring Nanomaterials showed a differential antiproliferative activity between breast triplenegative tumour cells and breast nontumourigenic cells. Besides, the same PVP-AgNP formulation significantly reduces the tumour volume of these aggressive tumours that are difficult to treat [13].

Our research group has studied a commercially available PVP-AgNP formulation known as Argovit ${ }^{\mathrm{TM}}$ that has been very effective as an antimicrobial [14, 15], antifungal [15], and antiviral agent [16-18]. This formulation also has been a determining factor in the rapid healing of diabetic foot ulcers [19]. Moreover, these nanoparticles inhibit the growth of human tumour cell cultures of the breast, lung, prostate, cervix, and colon. The main death pathway activated was apoptosis, probably triggered by the overproduction of reactive oxygen species (ROS). There was no necrosis, and neither was there evidence of DNA-damage at the effective inhibitory concentrations determined for each tumour cell line [20].

Considering the growth inhibition activity of these PVP-AgNPs on human tumour cell lines, in this work, we show a systematic study of the in vitro and in vivo effect of well-characterized AgNPs on murine melanoma models. Cytotoxicity, cell death pathway induction, and ROS generation were analysed in vitro. In addition, a subcutaneous melanoma model in C57BL/6J mice was performed following the protocol recommended by the National Institute of Health (NIH) [21], where tumour volume, survival rate, haematological parameters, and genotoxicity of the treatments were evaluated.

\section{Materials and Methods}

2.1. Silver Nanoparticles (AgNPs). Silver nanoparticles used in this work were donated by Dr. Vasily Burmistrov from the Scientific and Production Center Vector-Vita (Russia). Argovit $^{\mathrm{TM}}$ is a formulation of PVP-coated AgNPs highly dispersed in water with an overall concentration of $200 \mathrm{mg} / \mathrm{mL}$ (20\%). The content of metallic silver is $12 \mathrm{mg} / \mathrm{mL}$ stabilized with $188 \mathrm{mg} / \mathrm{mL}$ of PVP. Dilutions of AgNPs were prepared with distilled and sterile water and were kept at $4^{\circ} \mathrm{C}$ in darkness.
2.2. Silver Nanoparticle Characterization. Dynamic light scattering (DLS) (Malvern Instruments Zetasizer Nano NS model DTS1060; $\lambda=532 \mathrm{~nm}$ ) was used to determine the hydrodynamic diameter and the zeta potential. Characterization of optical properties was done with the Cary $60 \mathrm{UV}$-vis spectrophotometer (Agilent Technologies) in the range of 200 to $900 \mathrm{~nm}$. Morphology and size distribution were determined by HR-TEM using a JEOL JEM-2010 microscope. Also, lyophilized AgNPs were characterized by FTIR-ATR in a range of 400 to $4000 \mathrm{~cm}^{-1}$ with a resolution of $2 \mathrm{~cm}^{-1}$ on a universal diamond ATR Top Plate accessory (PerkinElmer). The sample spectrum was compared with that of standard solid PVP (MW $100 \mathrm{kDa})$. The silver content of Argovit $^{\circledR}$ was determined by ICP-OES (Varian Vista-MPX CCD Simultaneous ICP-OES).

2.3. Cell Culture. B16-F10, murine skin melanoma cells from C57BL/6J mice, were purchased from ATCC ${ }^{\circledR}$ (ATCC ${ }^{\circledR} \mathrm{CRL}$ $6475^{\mathrm{TM}}$ ) and maintained in DMEM high-glucose media (Sigma-Aldrich, 51435C) supplemented with $10 \%(v / v)$ of heat-inactivated Foetal Bovine Serum (FBS, Biowest, S1650) and $2 \mathrm{mM}$ of L-glutamine (Sigma-Aldrich, G5792) at $37^{\circ} \mathrm{C}$ in a humidified atmosphere with $5 \% \mathrm{CO}_{2}$. Subculturing was performed every 2 days.

2.4. Antiproliferative Activity. B16-F10 cells $\left(1 \times 10^{5}\right)$ were seeded in 96-well plates with $195 \mu \mathrm{L}$ of DMEM highglucose supplemented media (Sigma-Aldrich, 51435C). Primary screening was done to determine $\mathrm{IC}_{50}$ values using the MTT assay kit (Bio-Vision MTT Cell Proliferation Assay Kit \#K299-1000) and ProBit analysis after $24 \mathrm{~h}$ of exposure. After that, the $\mathrm{IC}_{50}$ of $\operatorname{AgNPs}(4.2 \mu \mathrm{g} / \mathrm{mL})$ and Cisplatin $(2 \mu \mathrm{g} / \mathrm{mL}$, CisPt) were employed to determine the cell growth behaviour at $6,12,18$, and $24 \mathrm{~h}$. The proliferation kinetics was determined by flow cytometry in Attune NxT equipment. Cell viability was determined using the Vybrant ${ }^{\mathrm{TM}}$ CFDA SE Cell Tracer Kit and propidium iodide (PI) (Thermo Fisher Scientific, V12883) following the provider's protocol.

Determination of apoptosis and necrosis cell death pathway was determined with the Alexa Fluor ${ }^{\circledR} 488$ Annexin V/Dead Cell Apoptosis Kit (Thermo Fisher Scientific, V13241). ROS generation was analysed by the DCFDA Cellular ROS Detection Assay Kit (Abcam, 139476) and with the MitoSOX ${ }^{\mathrm{TM}}$ Red Mitochondrial Superoxide Indicator for live-cell imaging (Invitrogen, M36008).

2.5. Experimental Animals. We purchased seventy 8-10week-old C57BL/6JNHsd male mice from Envigo, Mexico. Mice were divided and assigned randomly to polycarbonate cages into 6 groups of 10 mice each and two more groups of 5 mice each. The latter groups were used as untreated controls for haematological and genotoxicity trials. Mice were maintained at $25^{\circ} \mathrm{C}$ temperature, $60 \%$ humidity, and 12/12-hour light-dark cycle and fed at libitum. The experimental protocol was approved on June 19, 2018, by the Ethical Committee of the Health Sciences School from the Autonomous University of Baja California, Mexico with file number $001 / 2018$. 
Melanoma induction in C57BL/6JNHsd mice was performed as recommended by the USA NIH [21]. First, B16-F10 cells in the logarithmic growth phase were harvested for injection; after guaranteeing viability with trypan blue $(>90 \%)$, cell concentration was adjusted to $1 \times 10^{6} \mathrm{cell} / \mathrm{mL}$ in ice-cold Hank's Balanced Salt Solution (HBSS, Biowest, L0606).

Mice of $20 \mathrm{~g}$ weight were inoculated by subcutaneous administration of $100 \mu \mathrm{L}$ cell suspension $\left(1 \times 10^{5}\right.$ cells/ mouse). The appearance of a "bleb" indicates the correct subcutaneous administration. After cell administration, mice were placed in the corresponding cage. Tumours became palpable in 12 days, and at this point the antitumour trials were initiated.

2.6. Antitumour Activity. The mice with palpable tumours (10 per group) were administered subcutaneously each 3 rd day for 21 days with the corresponding dose of each treatment as follows: Group 1-negative control (injectable water); Group 2-positive control (CisPt, $2 \mathrm{mg} / \mathrm{kg}$ ); Group 3-vehicle control (PVP, $12 \mathrm{mg} / \mathrm{kg}$ ); Group 4-AgNPs, $3 \mathrm{mg} / \mathrm{kg}$; Group 5-AgNPs, $6 \mathrm{mg} / \mathrm{kg}$, and Group 6-AgNPs, $12 \mathrm{mg} / \mathrm{kg}$. Group 7 and Group 8 are healthy mice injected with water or PVP, respectively ( $n=5$ for each group), and used as negative control for the haematological parameters and genotoxicity.

All the AgNP doses were calculated according to the metallic silver content. Dilutions were prepared with injectable water from a stock solution of Argovit ${ }^{\circledR}$ with $12 \mathrm{mg} / \mathrm{mL}$ of metallic silver to obtain the work solutions at the final concentrations of 24,12 , and $6 \mu \mathrm{g} / \mathrm{mL}$. Then, $100 \mu \mathrm{L}$ was administered to each mouse according to the administration scheme previously described. Doses were chosen due to previous experiences with murine models [17]. The mice were examined daily, and tumours were measured every day of administration with a slide calliper. Tumour volume was determined with the Attia-Weiss formula. Furthermore, general characteristics (activity, hair appearance, and any apparent change) were also recorded.

After 21 days of the administration, the treatment was stopped and the animals observed for 7 more days. After that, the mice were anaesthetized with ketamine and euthanized by cardiac puncture to collect blood samples.

2.7. Genotoxicity Determinations. Drop blood samples were taken from the animals before they died (experimental Groups 1, 2, 3, and 5) or euthanized (Groups 4, 6, and 7). Two smears were made on cleaned microscope slides. The smears were air-dried, fixed in absolute ethanol for 10 minutes, and stained with acridine orange (CAS No. 10127023, Sigma-Aldrich).

The micronuclei in each sample were scored manually using a binocular microscope (Carl Zeiss, Axiostar Plus) with a fluorescent filter (IVFL, 450-490 nm). The number of micronucleated erythrocytes (MNE) in 10,000 total erythrocytes and the polychromatic erythrocytes (PCE) in 1000 total erythrocytes were evaluated.
2.8. Statistical Analysis. Viability, apoptosis, necrosis, ROS generation, and tumour volume data, were analysed with a two-way ANOVA $(P<0.05)$ followed by the Tukey post hoc test $(P<0.05)$ (GraphPad Prism). For relative survival $\%$ data, the Mantel-Haenszel chi-square statistic was used $(P<0.05)$ (GraphPad Prism).

\section{Results}

3.1. Silver Nanoparticle Characterization. A complete characterization of the sample provided by Prof. Burmistrov was performed. AgNPs are mainly spherical with an average size of $35 \pm 15 \mathrm{~nm}$ as determined by HR-TEM. The hydrodynamic diameter (summarized diameter of a metallic silver nanoparticle and PVP coating) determined by DLS was $70 \mathrm{~nm}$, and the $\zeta$ potential was $-15 \mathrm{mV}$. UV-vis analysis showed an absorption peak at $420 \mathrm{~nm}$ that corresponds to the plasmon surface resonance. The silver content of the concentrate solution was $12 \mathrm{mg} / \mathrm{mL}$, determined by ICP-OES.

The FTIR-ATR spectrum shows peaks corresponding to the hydroxyl vibration of unbound water $(v \mathrm{OH})$ at $3406 \mathrm{~cm}^{-1}$, carbonyl stretching at $1650 \mathrm{~cm}^{-1}(\nu \mathrm{C}=\mathrm{O})$, symmetrical stretching of nitrogen in the ring at $1269 \mathrm{~cm}^{-1}$ $\left(\nu_{s} \mathrm{C}-\mathrm{H}\right)$, and asymmetric $\left(\nu_{a s} \mathrm{C}-\mathrm{H}\right)$ stretching at 2948 and $2915 \mathrm{~cm}^{-1}$, respectively. Metallic silver determined by ICP-OES is $12 \mathrm{mg} / \mathrm{ml}$ (\% wt).

3.2. Cell Viability, Apoptosis, Necrosis, and Reactive Oxygen Species Quantification In Vitro. In this work, cellular viability, induction of apoptosis or necrosis, and ROS generation changes on murine melanoma cells B16-F10 after exposure to $\mathrm{IC}_{50}$ of AgNPs $(4.2 \mu \mathrm{g} / \mathrm{mL})$ or CisPt $(2.0 \mu \mathrm{g} / \mathrm{mL})$ were evaluated at $6,12,18$, and $24 \mathrm{~h}$. The main changes in cellular viability were observed in the first $6 \mathrm{~h}$ following the administration of the agents, CisPt or AgNPs. After that, the effect was maintained until the last record at $24 \mathrm{~h}$ (Figure 1).

From the record of cellular viability, both agents AgNPs and CisPt present the same antiproliferative effect $(53.95 \pm 1.88$ and $53.62 \pm 1.04$, respectively), but the cell death pathways induced are quite different. After $6 \mathrm{~h}$ of exposure, $45.97 \pm 1.88 \%$ of apoptosis was observed on cells treated with AgNPs, twofold higher than the apoptotic cells found when exposed to CisPt $(22.31 \pm 1.72 \%$, Figure 1$)$. On the other hand, treatment with AgNPs produces less than $0.1 \%$ of necrosis, while for CisPt it was $24.06 \pm 1.09 \%$. For CisPt, both cell death pathways were induced practically at the same rate (Figure 1). Behaviour found after $6 \mathrm{~h}$ of exposure was maintained until the final determination was made at $24 \mathrm{~h}$ of exposure. Complete data of cellular viability, apoptosis, and necrosis can be consulted in the supplementary material Table S1.

The most significant reactive oxygen species (ROS) generation was found after exposure of $6 \mathrm{~h}$ to CisPt or AgNPs (Figure 2) and shows an inverse relationship with cellular viability. Cells treated with CisPt reached the maximal ROS production after $6 \mathrm{~h}$ of exposure (20.27 $\pm 1.09 \%)$; meanwhile, the highest ROS production induced by AgNPs was observed at $12 \mathrm{~h}(19.50 \pm 0.35 \%)$. 


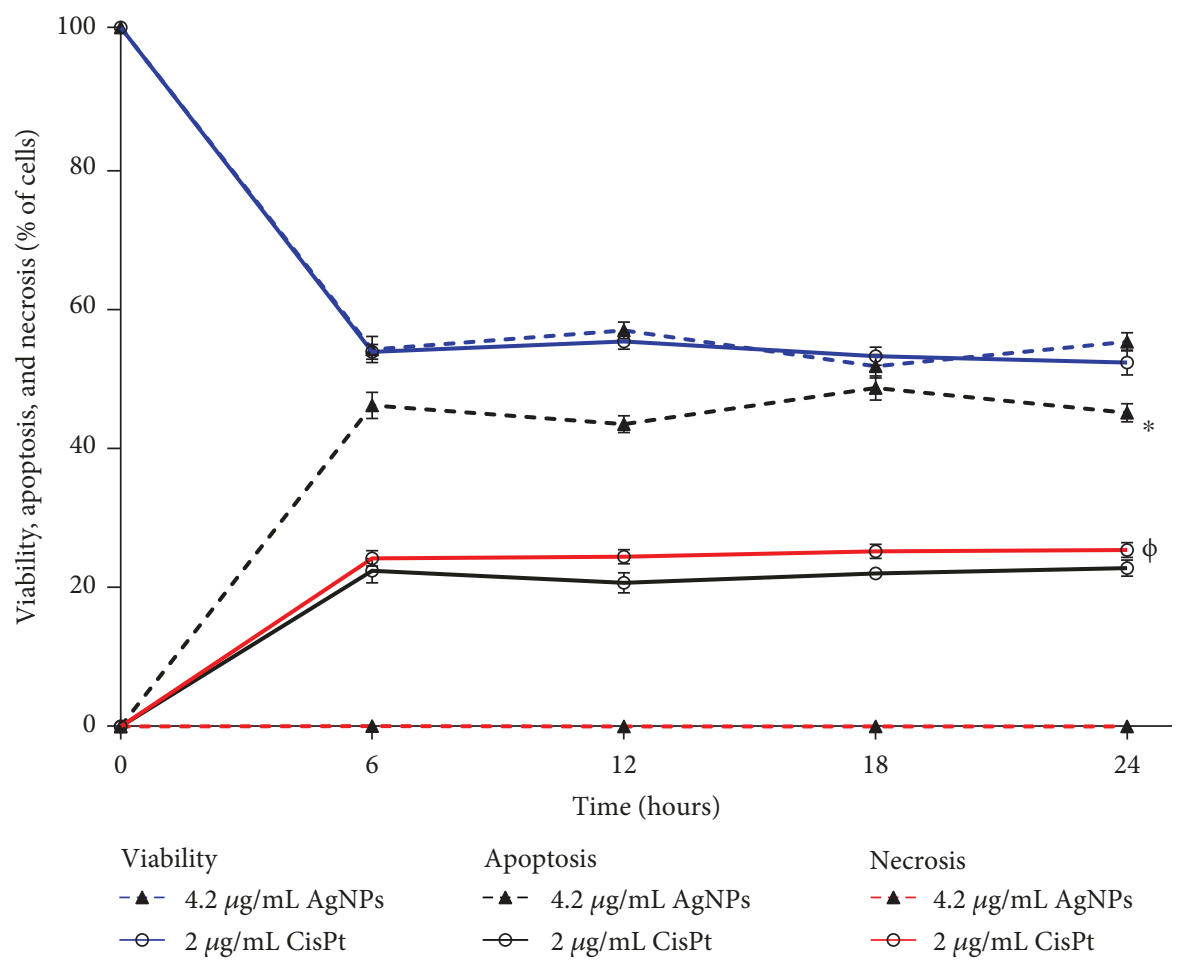

Figure 1: Viability, apoptosis, and necrosis determined in B16-F10 cell cultures treated with AgNPs or CisPt. Determinations were done at 6, 12,18 , and $24 \mathrm{~h}$ in melanoma cell cultures treated with the concentrations of AgNPs or CisPt indicated in the graph. Viability, blue lines; apoptosis, black lines; necrosis, red lines. $*$ indicates a statistically significant difference of $P<0.05$ for apoptosis data. $\Phi$ indicates a statistically significant difference of $P<0.05$ for necrosis data.

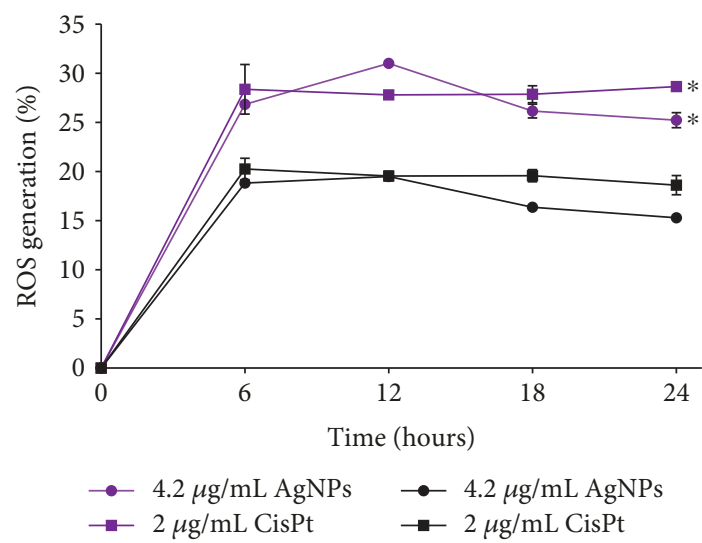

FIGURE 2: Reactive oxygen species production in melanoma cells treated with $\mathrm{IC}_{50}$ of AgNPs or CisPt. Quantification of ROS production in B16-F10 cell cultures treated with the $\mathrm{IC}_{50}$ of AgNPs or CisPt was performed by flow cytometry and fluorescent markers. Total ROS was determined with DCFDA (purple lines) and mitochondrial superoxide with MitoSOX (black lines). * indicates a statistically significant difference of $P<0.05$ comparing total ROS generation data with mitochondrial superoxide data.

The mitochondrial superoxide production has the same behaviour through time with that described for total ROS and corresponds to two-thirds of the total amount of ROS observed with $31.02 \pm 0.45 \%$ for AgNPs and $28.38 \pm 2.52 \%$ for CisPt. The most important difference between the treatments is that CisPt induces a sustained ROS generation after
$6 \mathrm{~h}$ and until $24 \mathrm{~h}$, while a decrease in ROS generation was observed after $12 \mathrm{~h}$ of exposure when melanoma cells were treated with AgNPs (Figure 2). All data of ROS production through time can be consulted in supplementary material Table S2.

3.3. Antitumour Activity. Tumour volume, as well as signs of illness, were observed throughout the experiment after the treatment administration described in Materials and Methods. Tumour volume increased in all mice with or without treatment. Mice with tumours treated with AgNPs did not stop eating or drinking through the whole experiment. Mice with the tumour but untreated, as well as those treated with CisPt or PVP, presented lethargy and loss of appetite.

Mice injected with water developed tumours of around $1500 \mathrm{~mm}^{3}$ and died 7 days after the tumour become palpable. The tumour volume in animals treated with PVP or CisPt presented a similar tumour volume (around $1500 \mathrm{~mm}^{3}$ ) after 9 days of the start of treatment (21st day in Figure 3). On the other hand, mice treated with AgNP doses of 3, 6, and $12 \mathrm{mg} / \mathrm{kg}$ exhibited a tumour volume within the range of $722-837 \mathrm{~mm}^{3}$. This represents a 50-60\% tumour growth inhibition elicited by the AgNP treatments compared with PVP $\left(1,890 \mathrm{~mm}^{3}\right)$, CisPt $\left(1,704 \mathrm{~mm}^{3}\right)$, or water $\left(1,500 \mathrm{~mm}^{3}\right)$. It is important to recall that all mice injected with water died on the 7 th day of treatment (Figure 3).

For the 11th day of treatment (day 23 in Figure 3), while the tumour growth rate in animals treated with any of the three doses of AgNPs increases in a quite similar way 


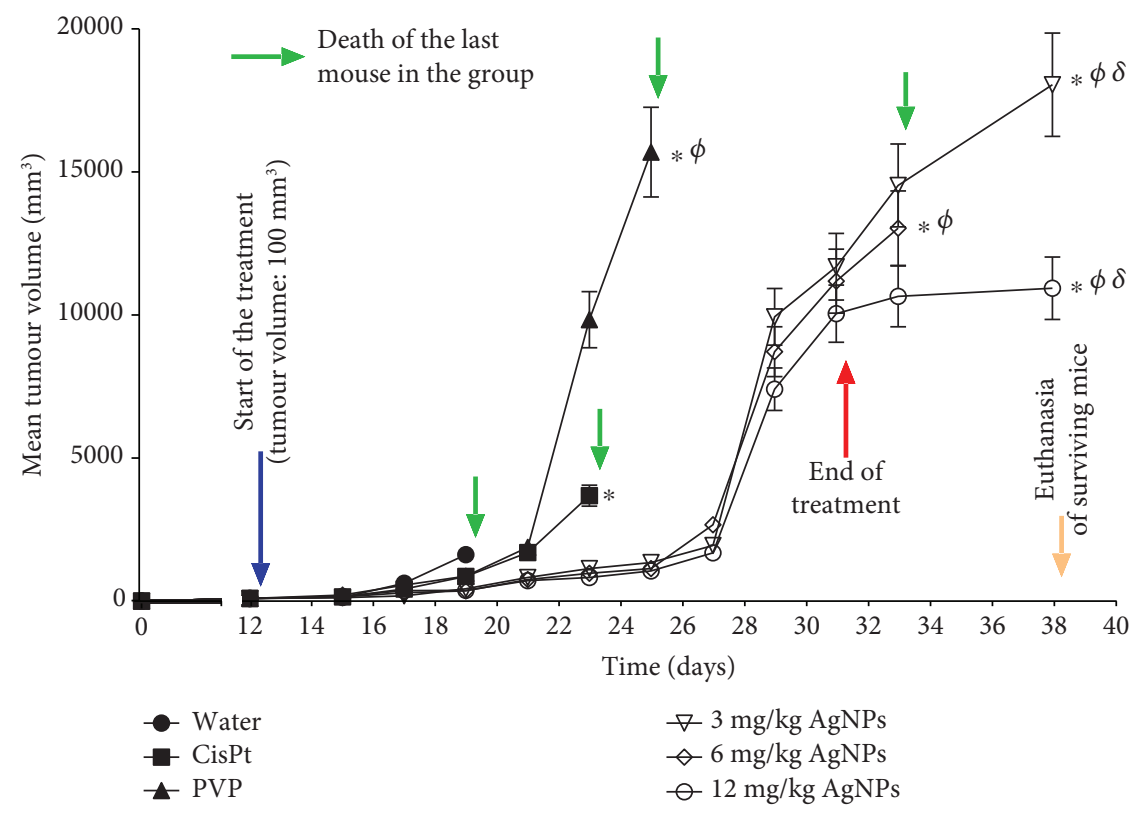

(a)
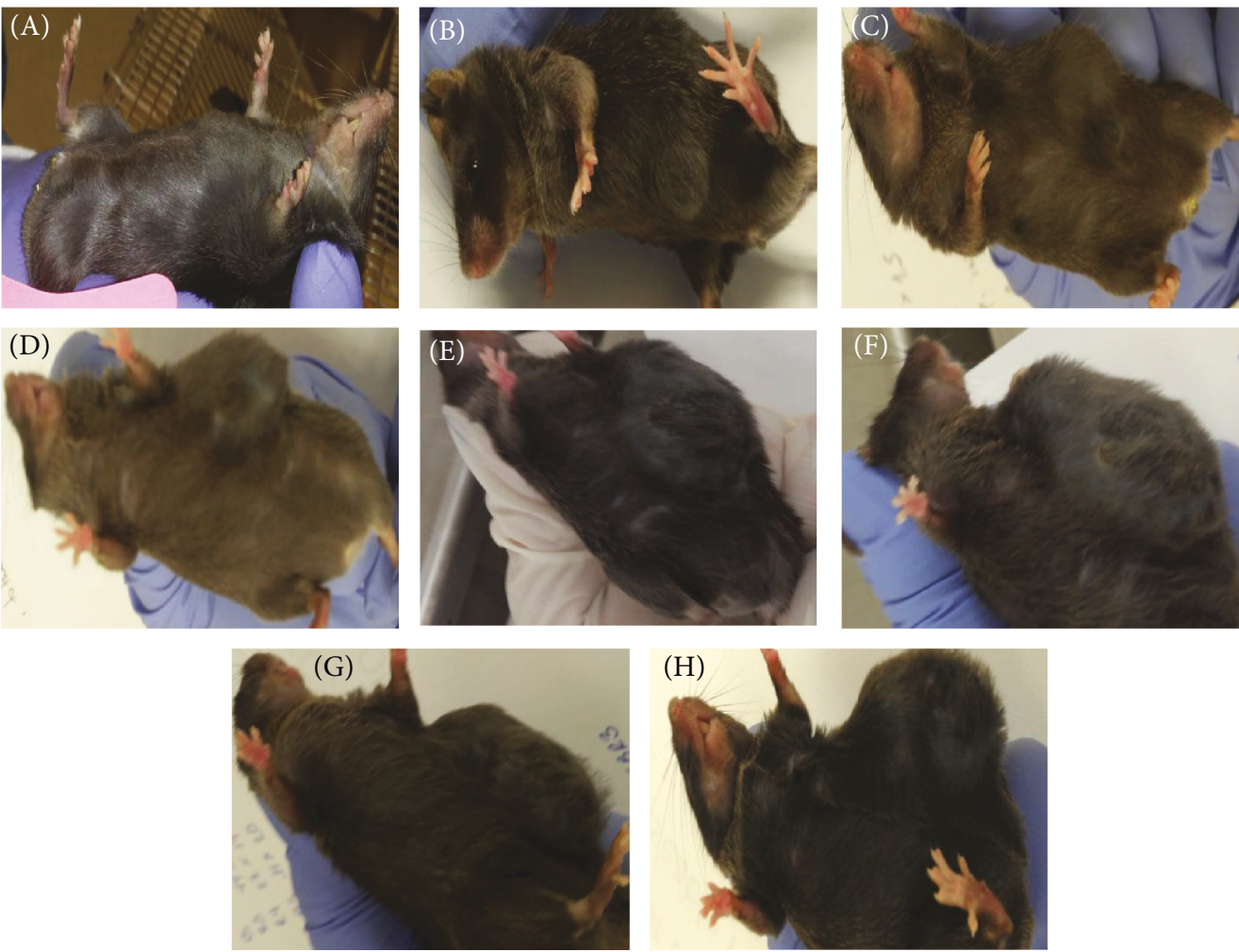

(b)

Figure 3: (a) Mean melanoma tumour volume as a function of time (days). Mice treated with injectable water were used as negative controls (water); mice treated with $2 \mathrm{mg} / \mathrm{kg}$ of Cisplatin (CisPt), $12 \mathrm{mg} / \mathrm{kg}$ of PVP (PVP), and 3, 6, or $12 \mathrm{mg} / \mathrm{kg}$ of AgNPs are indicated in the figure. Melanoma cells were inoculated subcutaneously at the beginning of the experiment (black arrow); treatments start when tumours were $100 \mathrm{~mm}^{3}$ (blue arrow). Treatments ended after 21 days (red arrow). Tumour volume determination was stopped when all mice in the group died (green arrows). 7 days after the end of the treatments (yellow arrow), surviving mice were euthanized. $*$ indicates a statistically significant difference of $P<0.05$ comparing groups with the group treated with water. $\Phi$ indicates a statistically significant difference of $P<0.05$ comparing groups with the group treated with CisPt. $\delta$ indicates a statistically significant difference of $P<0.05$ comparing between AgNP doses. (b) Pictures showing mouse without melanoma (A), when tumour reached $100 \mathrm{~mm}^{3}$, and when this tumour volume was reached in mice with the following corresponding treatments $(\mathrm{C}-\mathrm{H})$ : $(\mathrm{C})$ water, (D) CisPt, (E) PVP, and (G) $6 \mathrm{mg} / \mathrm{kg}$. The surviving mice were euthanized on the 38th day: (F) AgNP $3 \mathrm{mg} / \mathrm{kg}$ and $(\mathrm{H}) \mathrm{AgNP} 12 \mathrm{mg} / \mathrm{kg}$. The last mice that died are marked with green arrows in (a). 


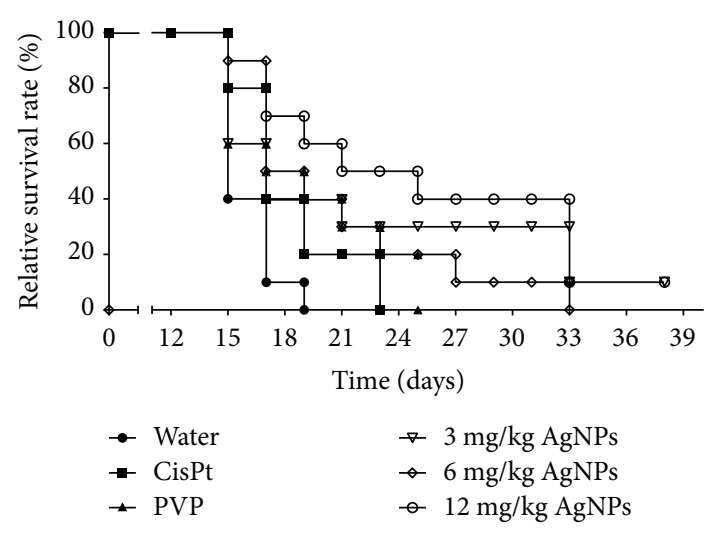

FIgURE 4: Kaplan-Meier plot showing the relative survival rates of mice treated with AgNPs or CisPt. Mice without melanoma and without treatment were used as negative controls (healthy mice, $100 \%$ survival rate). Mice with melanoma and injected with water (water), $2 \mathrm{mg} / \mathrm{kg}$ of Cisplatin (CisPt), $12 \mathrm{mg} / \mathrm{kg}$ of PVP (PVP), and 3 , 6 , or $12 \mathrm{mg} / \mathrm{kg}$ of AgNPs are identified at the bottom of the figure. $*$ and $\Phi$ indicate a statistically significant difference of $P<0.05$ comparing groups treated with AgNPs with groups treated with water and CisPt, respectively.

(tumour volume in the range of $837-1,142 \mathrm{~mm}^{3}$ ), animals treated with CisPt or PVP showed tumours with a volume of 3,500 and $9,500 \mathrm{~mm}^{3}$, respectively. These values represent a $72 \%$ reduction in tumour growth caused by the administration of AgNPs compared with CisPt and a 90\% reduction compared with PVP.

The evaluated doses of AgNPs did not show differences between them regarding tumour growth until the 19th day of treatment, which also was the last day of treatment. However, in the last seven days of the experiment (the 32nd-38th day in Figure 3), sharp differences were observed. The last surviving mouse of the group treated with $6 \mathrm{mg} / \mathrm{kg}$ died 2 days after the end of the treatment (day 33 in Figure 3), while on the group of mice treated with 3 and $12 \mathrm{mg} / \mathrm{kg}$ of AgNP, a mouse of each group survived the 7 days of the observation period.

Surviving mice of the experimental groups treated with 3 and $12 \mathrm{mg} / \mathrm{kg}$ of AgNPs show tumour volumes at the end of the observational period of 18,000 and $11,000 \mathrm{~mm}^{3}$, respectively (on the 38th day of Figure 3). Thus, it seems that a dose of $12 \mathrm{mg} / \mathrm{kg}$ of AgNPs inhibited the tumour growth by almost $50 \%$ compared with the treatment of $3 \mathrm{mg} / \mathrm{kg}$ (Figure 3), which strongly suggest a dose-dependent behaviour.

Figure 4 schematically shows the relative survival rate of mice treated with the different agents. On the 11th day of treatment (day 23 in Figure 4), the death of the last mouse of the group treated with CisPt was registered, while $50 \%$ of the mice treated with $12 \mathrm{mg} / \mathrm{kg}$ of AgNPs were still alive. At the end of the treatment scheme (day 33 in Figure 4), the life expectancy of the surviving individuals treated with AgNPs increased by 12,8 , and 6 days compared with those injected with water, CisPt, or PVP, respectively (Figure 4). At the end of the experiment, mice treated with 3 or $12 \mathrm{mg} / \mathrm{kg}$ of AgNPs survived 19, 15, and 13 days more than those treated with water, CisPt, or PVP, respectively. This represents a life expectancy of mice treated with AgNPs almost 4-times higher compared with those injected with water, and more than double compared with those mice treated with $2 \mathrm{mg} / \mathrm{kg}$ of CisPt (Figure 4). In our knowledge, this is the first time that those effects are observed with an AgNP treatment on an in vivo melanoma model.

3.4. Haematological Parameters. To complete the profile of the survivor animals to the treatment scheme (mice of groups treated with 3 and $12 \mathrm{mg} / \mathrm{kg}$ ), their haematological parameters were compared with those observed in healthy mice injected with water or PVP (negative control groups, $n=5$ for each group).

In general terms, the parameters of individuals treated with AgNPs were within the ranges considered as normal for these mice [22], with the exception of haematocrit (HCT) and haemoglobin (HGT), where an important decrease was observed for both groups treated with 3 and $12 \mathrm{mg} / \mathrm{kg}$ of AgNPs. Besides, an increase on white blood cells and lymphocytes was observed, but only in the mouse treated with the AgNP dose of $3 \mathrm{mg} / \mathrm{kg}$ (Figure 5).

3.5. Genotoxicity. Finally, the quantification of micronuclei on erythrocytes (MNE) in 10,000 of the total erythrocytes that indicate genotoxic damage and the counting of polychromatic erythrocytes (PCE) in 1000 total erythrocytes that indicate myelosuppression (cytotoxic effect) were performed.

Tail blood samples from healthy mice, surviving mice of the AgNP treatments of 3 and $12 \mathrm{mg} / \mathrm{kg}$, and from the last survivor of the other treatment groups (untreated controls with melanoma and mice with melanoma injected with PVP, CisPt, and AgNP $6 \mathrm{mg} / \mathrm{kg}$, respectively) were used to identify genotoxic and cytotoxic effects of the treatments.

Results show that mice with melanoma present practically the same MNE count as that of healthy mice, both within the range of 6-14 MNE reported for this strain [23] (marked with red lines in Figure 6). CisPt produces a higher number of MNE with an MNE count of 23. Interestingly, the dose of $6 \mathrm{mg} / \mathrm{kg}$ of AgNP generates a higher count of MNE than the upper limit reported. PVP produces $14 \mathrm{MNE}$, while AgNP doses of 3 and $12 \mathrm{mg} / \mathrm{kg}$ produce 4 and $8 \mathrm{MNE}$, respectively.

On the other hand, it is clear from Figure 6 that the counting of PCE in the mouse with melanoma is substantially lower than that found in the healthy one. For CisPt, a small increase compared with the positive control was found, while a dose-dependent behaviour was observed for AgNP doses; however, none of them are comparable with the effect observed for PVP, which practically overturned the myelosuppression promoted by melanoma and reached PCE levels like those found in the healthy mice.

\section{Discussion}

During the past decades, metal nanoparticles [24-26] and particularly AgNPs ([27]) have shown a real potential to inhibit tumour cell proliferation. It has been published that AgNP toxicity could be related with the release of $\mathrm{Ag}^{+}$ions 


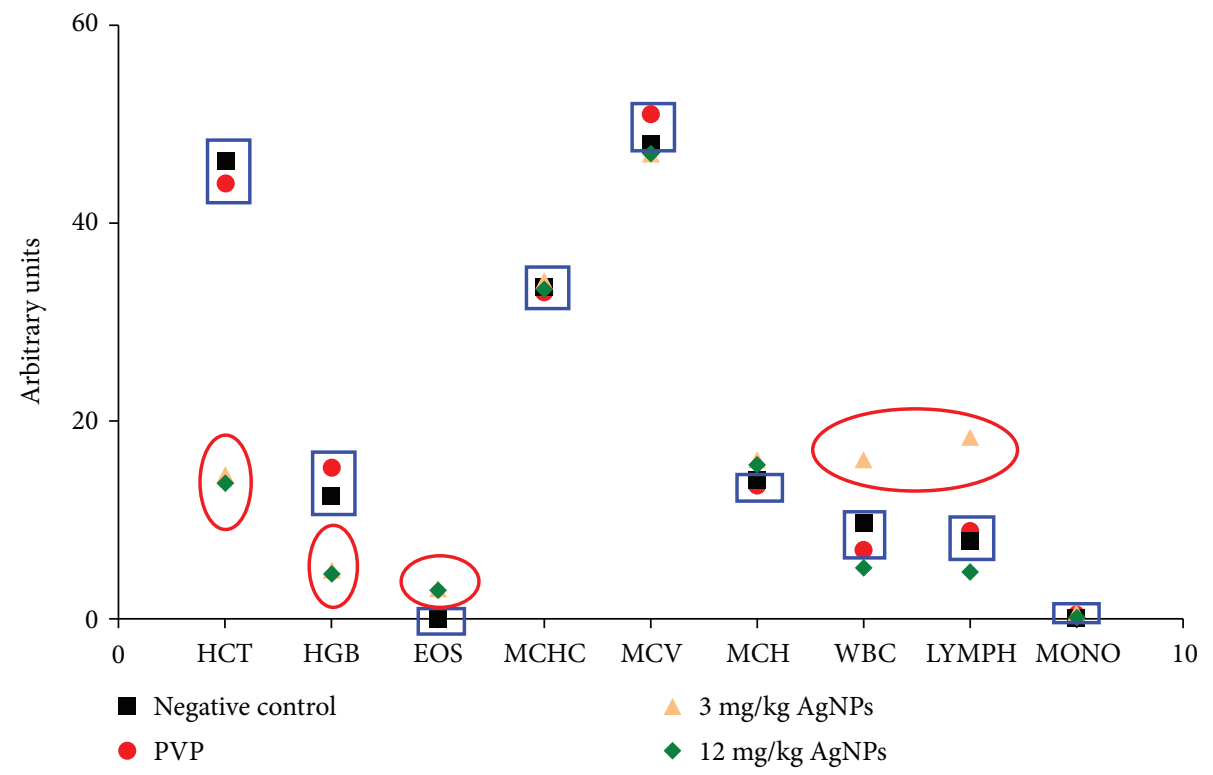

FIgURE 5: Haematological parameters in the surviving animals at the end of the study. Haematocrit (HCT), haemoglobin (HGB), eosinophils (EOS), mean corpuscular volume (MCV), mean corpuscular haemoglobin concentration (MCHC), white blood cells (WBC), lymphocytes (LYMPH), and monocytes (MONO) were determined in surviving mice treated with AgNPs and in mice without melanoma injected with water or PVP. HCT, HGB, WBC, and LYMPH were out of the range reported as normal (blue boxes) and those outside the normal ranges in mice treated with AgNPs (red circles).

[28-30] or to the whole nanoparticles $[28,29]$ which induce ROS generation, modifying the transmembrane potential of mitochondria and, in turn, trigger the activation of several cell death pathways.

The physicochemical properties of AgNPs such as size, coating, and metal content have been related with their cytotoxic effect in mammalian cells [31-33]. In human cell lines, the size of AgNPs plays a key role in the effects on viability, membrane integrity, and ROS generation [32, 34-36]. Specifically, a smaller size of AgNPs induce a higher cytotoxicity [37-40]. On the other hand, coating agents provide different stability degrees that directly influence the cytotoxic and genotoxic effects [11,41, 42].

The effect of the AgNP formulation studied on this work on the B16-F10 murine melanoma cells with an $\mathrm{IC}_{50}$ of $4.2 \mu \mathrm{g} / \mathrm{mL}$ after $24 \mathrm{~h}$ of exposure is quite similar to that found for human tumour cell lines of the cervix (HeLa), breast (MDA-MB-231 and MCF-7), prostate (DU-145), colon (DLD-1 and HT-29), and lung (H-1299 and H-1437). For all of them, the $\mathrm{IC}_{50}$ values found were within the concentration range of 1.82 to $3.43 \mu \mathrm{g} / \mathrm{mL}$ after the same exposure time. As found for B16-F10 in this work, in all types of the tumour cells evaluated, the main cell death pathway induced is apoptosis and the cellular viability showed an inverse relationship with ROS overproduction. At the $\mathrm{IC}_{50}$ value determined for each tumour cell, no DNA damage was found according to the comet assays performed [20].

Interestingly, according to the proliferation kinetics, the main changes elicited by AgNPs on B16-F10 cells were not produced at $24 \mathrm{~h}$ but only after $6 \mathrm{~h}$ of exposure (Figure 1). After this time of exposure, cell viability and ROS overproduction have shown an inverse relationship (Figure 2). Besides, apoptosis reached its highest levels without necrosis evidence (Figure 1). Consequently, AgNPs need only $6 \mathrm{~h}$ to provoke the cellular damage that leads melanoma cells to die by apoptosis (Figures 1 and 2).

Despite that both the agents AgNPs and CisPt produce similar effects on melanoma cells regarding cell viability and ROS overproduction, the final consequence is quite different. While the former induces only apoptosis as the main cell death pathway, the latter induces practically the same amount of apoptosis and necrosis.

On in vitro conditions, the CisPt-DNA adduct can be formed after $1-3 \mathrm{~h}$ in the blood cells and tumour tissue of cancer patients [43]. Thus, the quick obtainment of the CisPt-DNA adduct, the decrease of glutathione (GSH) [44], and the production of ROS in the mitochondria that, in turn, collapses energy production [45] could be independent of concomitant factors that contribute to the presence of 40 times more necrosis after CisPt administration compared with exposure to AgNPs.

Although the molecular mechanism of cytotoxicity elicited by this AgNP formulation is still not fully elucidated, these results represent an important advantage for AgNPs compared with CisPt because necrotic cellular debris promotes a proinflammatory response that is associated with tissue damage, processes not observed with the induction of programmed cell death ([46]).

Furthermore, the antitumour activity observed in mice treated with CisPt is completely different from that observed with AgNP treatments. The animals treated with CisPt died on the 11th day after the start of the treatment. During this time, they show lethargy and loss of appetite. This symptomatology could be related to the rapid and uncontrollable damage produced at the cellular level, which could be promoted by ROS overproduction in mitochondria and the alteration 
Genotoxicity

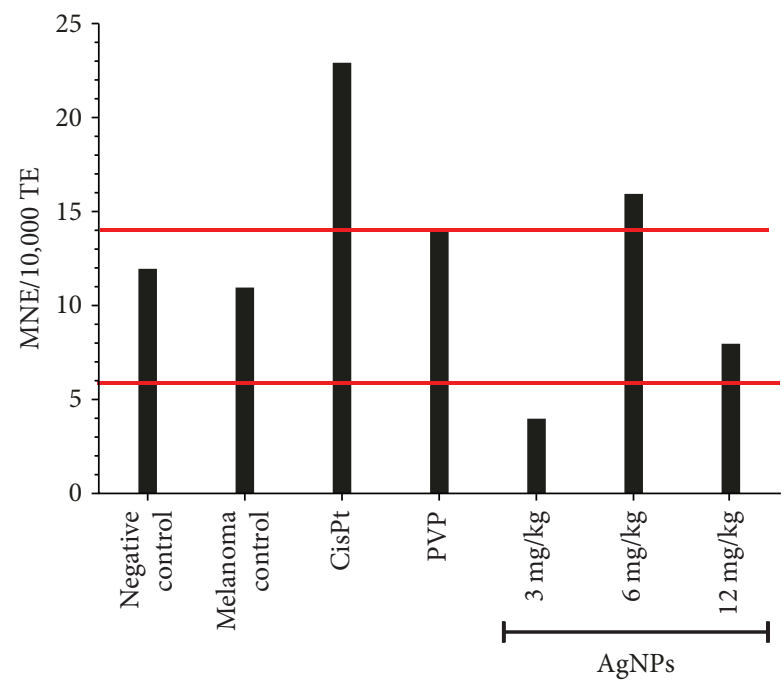

(a)

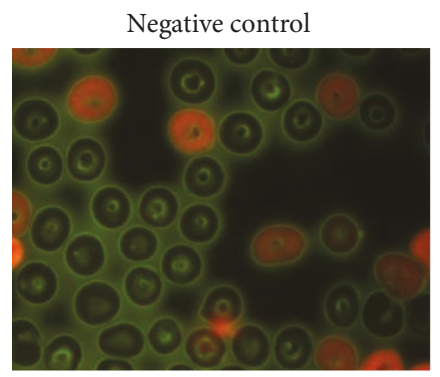

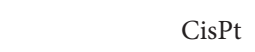

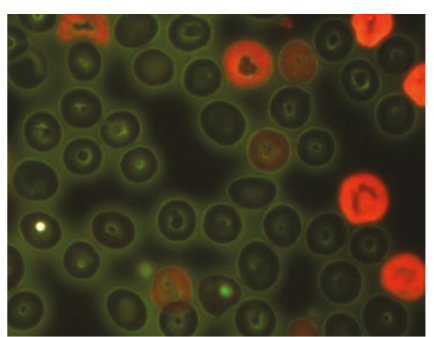

Cytotoxicity

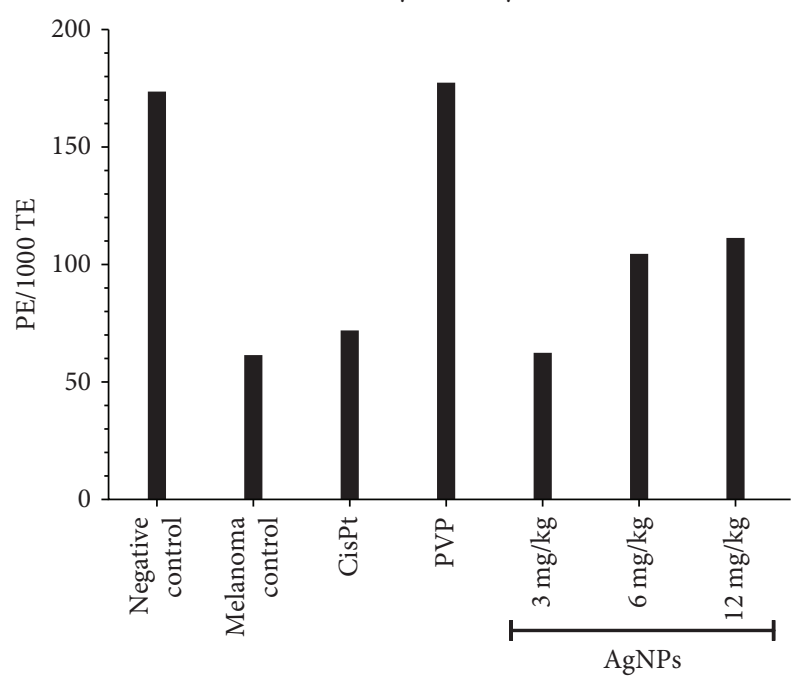

(b)
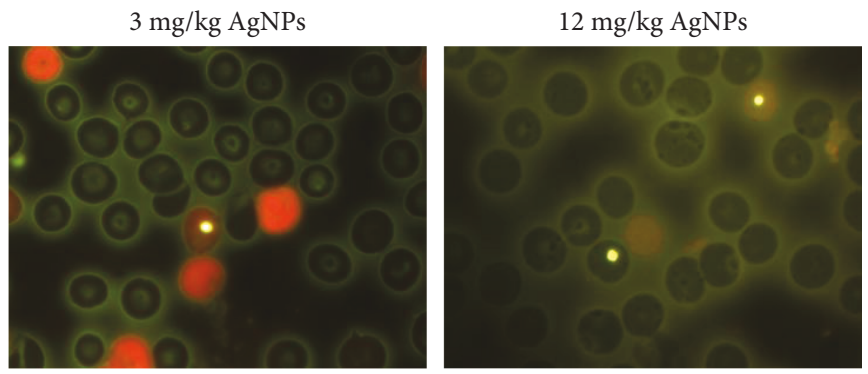

(c)

FIGURE 6: Cytotoxic and genotoxic effects quantified on erythrocytes from circulating blood samples. (a) Average of micronucleated erythrocytes (MNE) scored in 10,000 of total erythrocytes, (b) polychromatic erythrocytes (PCE) in 1000 erythrocytes, and (c) representative images of scored polychromatic erythrocytes (polychromatic erythrocytes, red; normochromatic erythrocytes, green; micronuclei, yellow). Healthy mice (negative control), untreated mice (melanoma control), and mice with melanoma treated with CisPt, PVP, and the indicated doses of AgNPs. Red lines indicate the normal micronuclei range reported for C57BL/6J mice, polychromatic erythrocytes (red), normochromatic erythrocytes (green), micronuclei (yellow).

TABle 1: Physicochemical properties of AgNPs employed on in vivo murine melanoma models.

\begin{tabular}{lccc}
\hline Property & Lin et al. [47] & Kang et al. [48] & This work \\
\hline AgNP size $(\mathrm{nm})$ & $58.8 \pm 1.7$ & 2.3 & $35 \pm 15$ \\
Protective agent & PVP & PVP & PVP \\
$Z$ potential $(\mathrm{mV})$ & $-12.9 \pm 1.1$ & -0.28 & $\mathrm{ND}^{*}$ \\
Metallic silver content $(\% \mathrm{wt})$ & $\mathrm{ND}^{*}$ & $\mathrm{NA}^{\dagger}$ & 1.2 \\
Initial tumour diameter $(\mathrm{mm})$ & $4-6$ & 1,5 , and 10 & 10 \\
Used dose: metallic silver $(\mathrm{mg} / \mathrm{kg})$ & 1.5 & $\mathrm{NA}^{\dagger}$ & 3,6 , and 12 \\
Days of administration in treatment & 5 & $\mathrm{NA}^{\dagger}$ & 21 \\
Dosage frequency & $24 \mathrm{~h}$ & $\mathrm{NA}^{\dagger}$ \\
Days without treatment before sacrifice & 8 & & $78 \mathrm{~h}$ \\
\hline
\end{tabular}

${ }^{*}$ ND: not determined. ${ }^{\dagger} \mathrm{NA}$ : not applicable.

of the DNA structure that, finally, triggers necrosis as the main cell death pathway.

Unlike the treatment with CisPt, the AgNP treatments achieved a remarkable survival time with the three concentrations assayed. At least one mouse of the groups treated with 3,6, or $12 \mathrm{mg} / \mathrm{kg}$ of AgNPs reached the 21st day of the treatment alive; this represents almost a quadruplication of the lifespan compared with that of mice injected with water and doubling the lifespan compared with that of mice treated with CisPt. 
As far as we know, there are only two papers that analyse the effect of AgNPs in an in vivo melanoma murine model. In the first work [47], a study of 17 days was performed using wortmannin, AgNPs, or a combination of both. Daily administration for 5 days starting with a tumour volume range of $50-100 \mathrm{~mm}^{3}$ was used. Animals were euthanized eight days after the end of the treatment (13 days of observation).

This treatment scheme is quite different from that recommended for the NIH, but it is important to note that the authors of the work were focused in the modulation of autophagy to enhance the antiproliferative effect of AgNPs against cancer cells [47]. In general, Lin et al. found a much lower tumour growth inhibition than what we found in the same time window (thirteen days after starting treatment).

The largest tumour volume they found in their controls on day 13 after the treatment began is about $1200 \mathrm{~mm}^{3}$; those treated with their AgNPs had a tumour volume close to $500 \mathrm{~mm}^{3}$ and those treated with the combination of AgNPs and wortmannin had a tumour volume of around $300 \mathrm{~mm}^{3}$. In this work, we found that on the 13th day after treatment began mice injected with water and CisPt already died; meanwhile, the surviving mouse of the group injected with PVP had a tumour volume of $9500 \mathrm{~mm}^{3}$ and all mice treated with AgNPs presented tumour volumes between 800 and $1150 \mathrm{~mm}^{3}$ (Figure 3). Unfortunately, these are not conclusive data due to the differences on the initial tumour volume, dosage frequency, days of treatment, follow-up days, and an unknown silver content of the AgNPs used by them which do not allow us to make a direct comparison with the results found in this work.

The second article [48] is quite different because it is focused on the angiogenic capacity of AgNPs. The authors report that B16-F10 melanoma cells exposed to AgNPs and then injected intradermally in C57BL/6J mice induced angiogenesis in the area near to the tumour and increased the haemoglobin concentration within the tumour. Smaller nanoparticles $(2 \mathrm{~nm}$, Table 1$)$ elicited the vascularization around the tumour in the melanoma model, and the angiogenic effect is enhanced if the cells were previously exposed to AgNPs. The angiogenic effect elicited by low doses of AgNPs could promote the tumour growth, but this is reversed when the dose or the size of the nanoparticle increase [48].

On the other hand, AgNPs with a higher size $(53 \mathrm{~nm}$, Table 1) induce autophagy in melanoma cells with high concentrations or induce cell survival with lower concentrations. These works, including ours, are examples of the great impact that the size of nanoparticles with the same stabilizing agent has on murine melanoma. Unfortunately, the same cannot be said for the concentration of silver present in each study due to the lack of information (Table 1). The main similarities and differences between the characterization of AgNPs previously published and the AgNPs used in this work in an in vivo melanoma model are shown in Table 1.

A very important result from this work is that at the higher dose of AgNPs tested $(12 \mathrm{mg} / \mathrm{kg})$ the tumour growth seems to be inhibited, since the tumour volume remains constant during the whole observational period (seven days); that is, from the 31 st to the 38th day of the experiment (Figure 3).

This response must necessarily be related to the dosedependent behaviour observed on the EPC counting that could be interpreted as a lower myelosuppression effect as the AgNP doses increase. Also, this is consistent with the general behaviour of mice treated with AgNPs that continued to be active and kept on feeding, in spite of the size of the tumour. This is contrary to the behaviour observed on mice treated with CisPt and those from the negative control group (Figure 6). These results suggest a protective dose-dependent effect elicited by AgNP treatments (Figure 6).

From Figure 6, it is clear that the higher protection against the myelosuppressive effect is provided by the PVP. However, only the combination of PVP and metallic silver to obtain the AgNP formulation possesses both the protective effect against myelosuppression and the antitumour activity.

Moreover, no genotoxic effect was observed on AgNP treatments of 3 and $12 \mathrm{mg} / \mathrm{kg}$, both with an MNE counting below the upper limit of the range reported for this mouse [23] (marked in Figure 6 with red lines). Mice from the positive control group (with melanoma and without treatment) showed an MNE count within the marked range as well as the mice treated with PVP. In this sense, given that it has been reported that rodents are more sensitive to the genotoxic damage induced by AgNP than humans [49], one would expect very low damage caused by the administration of the AgNP formulation studied here in humans.

Conversely, samples from the last mouse of the group treated with CisPt showed almost double the MNE. This could be associated with the necrosis induction and the limited survival time observed on mice treated with this compound. It is known that platinum-based drugs, among them $\mathrm{CisPt}$, are genotoxic. This fact is related with the appearance of new tumours and drug resistance, which means that, even when the CisPt treatment is effective against a tumour, there is an oncogenic risk due to its genotoxic effect [50].

Regarding the behaviour observed for mice treated with $6 \mathrm{mg} / \mathrm{kg}$ of AgNPs, these experiments do not provide enough arguments to explain the death of the last mouse five days earlier than the other surviving animals treated with 3 and $12 \mathrm{mg} / \mathrm{kg}$ of AgNPs, respectively (Figure 6). But, as in the case of CisPt, the higher amount of MNE compared with basal values could be associated with the death of that mouse. Further experiments must be done to clarify this point.

Surviving mice present haematological parameters quite similar to that found in healthy mice [22], but the increases observed in WBC and LYMPH with the lowest dose of AgNPs $(3 \mathrm{mg} / \mathrm{kg})$ are consistent with the activation of immunological system cells by the low concentration of AgNPs [51]. On the other hand, the lower levels of haemoglobin (HGB) and haematocrit (HCT) on surviving mice treated with both 3 and $12 \mathrm{mg} / \mathrm{kg}$ of AgNPs can be interpreted as anaemia.

It has been reported that nanosized colloidal silver stabilized with PVP may induce HCT and HGB decrease [52], and other AgNPs promoted venous thrombus formation by platelet aggregation [53]. However, in this case, the observed decrease in HCT and HGC could be attributable to the 
development of melanoma itself. As shown in the Results, mice with melanoma but without treatment showed an important decrease on PCE counting. Therefore, the low levels of HCT and HGB could be the result of cumulative damage due to the progress of the disease and not because of a toxic effect of the administered AgNP.

For the purposes of avoiding as much as possible the anaemia in further studies, a systemic iron supplementation is proposed. It has been reported that this could be more effective than a twofold iron diet [54]. Also, it is known that a deficiency of other elements such as copper or selenium could be involved in the anaemia process $[55,56]$, but this is out of the scope of this work, and further analysis needs to be done to identify the cause and to prevent the anaemia.

Therefore, this work presents a systematic study for evaluating the antitumour effect of AgNPs in melanoma under standardized conditions, following NIH recommendations, and for providing the complete characterization of AgNPs, specifically the concentrations and doses of the active component, metallic silver. As a consequence, apoptosis induction, antitumour activity, lifespan increase, the absence of genotoxicity in blood samples, and the observed protective effect against myelosuppression elicited by melanoma on mice that have been exposed during 21 days to AgNPs is an irrefutable probe of the highest biocompatibility of these AgNPs compared with CisPt. All these results suggest that the possible adverse effects elicited by these AgNPs in humans might be less than the already known effects promoted by CisPt. This emphasizes the potential of AgNPs as an alternative for cancer treatment and urges the completeness of their preclinical studies.

\section{Conclusions}

This work is a systematic approach to evaluate the antiproliferative and antitumour effect of AgNPs in melanoma under standardized conditions following the recommended protocol by NIH. The AgNP formulation studied in this work, Argovit ${ }^{\circledR \mathrm{TM}}$, possesses a higher antitumour activity and biocompatibility on C57BL/6JNHsd mice inoculated with murine melanoma B16-F10 cells than that found in one of the most employed chemotherapeutic agents in melanoma treatment, CisPt.

The higher biocompatibility of these AgNPs compared with CisPt is manifested in vitro as apoptosis induction, which is the main cell death pathway after $6 \mathrm{~h}$ of exposure triggered by ROS overproduction, mainly on mitochondria. Meanwhile, their high capacity to reduce tumour growth, remarkable lifespan increase (quadruple compared with nontreated and double compared with those treated with CisPt), lack of genotoxic damage, and the possible protective effect against myelosuppression, elicited by the natural progression of melanoma, were observed in in vivo assays.

These findings show the importance of adequate physicochemical characteristics, such as size $(35 \mathrm{~nm})$, the optimal content of metallic Ag, and the effective metallic Ag/PVP ratio which provides AgNPs a high stability, to elicit the tumour growth rate decrease and to increase the life expectancy in individuals with one of the most aggressive skin cancers known. All these can be gained without evident genotoxic effects and even decreasing the myelosuppression provoked by the natural progression of the disease, urging the completeness of its preclinical studies.

\section{Data Availability}

The data used to support the findings of this study are available from the corresponding author upon request.

\section{Conflicts of Interest}

The authors declare that there is no conflict of interest regarding the publication of this paper.

\section{Authors' Contributions}

Lucía M. Valenzuela-Salas and Nayeli G. Girón-Vázquez contributed equally to this work.

\section{Acknowledgments}

J.C.G.R. and Y.T.M. acknowledge the continuous support from CONACyT-Red Farmoquímicos (294727). This work had the financial support from CONACyT-Red Internacional de Bionanotecnología con Impacto en Biomedicina, Alimentación y Bioseguridad (293418) and the Tomsk Polytechnic University Competitiveness Enhancement Program (VIU-ISHBMT-196/2018).

\section{Supplementary Materials}

Table S1: (related to Figure 1). Cellular viability, apoptosis, and necrosis recorded on B16-F10 cultures through time. Table S2: (related to Figure 2). ROS quantification by DCFDA and MitoSOX on B16-F10 exposed to AgNP and Cisplatin. (Supplementary Materials)

\section{References}

[1] World Health Organization, "Skin cancers," 2018, http://www .who.int/uv/faq/skincancer/en/index1.html.

[2] D. Schadendorf, A. C. J. van Akkooi, C. Berking et al., "Melanoma," The Lancet, vol. 392, no. 10151, pp. 971-984, 2018.

[3] L. Calderón, A. Peniche-Castellanos, L. Fierro-Arias, G. Montes de Oca-Sánchez, and I. Arellano-Mendoza, "Cutaneous melanoma: 12 years of experience," Dermatologia Revista Mexicana, vol. 61, no. 3, pp. 179-189, 2017.

[4] M. C. Foletto and S. E. Haas, "Cutaneous melanoma: new advances in treatment," Anais Brasileiros de Dermatologia, vol. 89, no. 2, pp. 301-310, 2014.

[5] B. Domingues, J. Lopes, P. Soares, and H. Populo, "Melanoma treatment in review," ImmunoTargets and Therapy, vol. 7, pp. 35-49, 2018.

[6] American Cancer Society, Cancer facts and figures 2018, American Cancer Society, 2018.

[7] S. Bhattacharyya, R. A. Kudgus, R. Bhattacharya, and P. Mukherjee, "Inorganic nanoparticles in cancer therapy," Pharmaceutical Research, vol. 28, no. 2, pp. 237-259, 2011.

[8] J. Li, Y. Wang, R. Liang et al., "Recent advances in targeted nanoparticles drug delivery to melanoma," Nanomedicine: 
Nanotechnology, Biology, and Medicine, vol. 11, no. 3, pp. 769794, 2015.

[9] S. J. Cameron, F. Hosseinian, and W. G. Willmore, "A current overview of the biological and cellular effects of nanosilver," International Journal of Molecular Sciences, vol. 19, no. 7, pp. 2030-2040, 2018.

[10] O. Bondarenko, K. Juganson, A. Ivask, K. Kasemets, M. Mortimer, and A. Kahru, "Toxicity of Ag, $\mathrm{CuO}$ and $\mathrm{ZnO}$ nanoparticles to selected environmentally relevant test organisms and mammalian cells in vitro: a critical review," Archives of Toxicology, vol. 87, no. 7, pp. 1181-1200, 2013.

[11] A. Ivask, N. H. Voelcker, S. A. Seabrook et al., "DNA melting and genotoxicity induced by silver nanoparticles and graphene," Chemical Research in Toxicology, vol. 28, no. 5, pp. 1023-1035, 2015.

[12] S. Ahlberg, A. Antonopulos, J. Diendorf et al., "PVP-coated, negatively charged silver nanoparticles: A multi-center study of their physicochemical characteristics, cell culture and in vivo experiments," Beilstein Journal of Nanotechnology, vol. 5, pp. 1944-1965, 2014.

[13] J. Swanner, J. Mims, D. Carroll et al., "Differential cytotoxic and radiosensitizing effects of silver nanoparticles on triplenegative breast cancer and non-triple-negative breast cells," International Journal of Nanomedicine, vol. 10, no. 1, pp. 3937-3953, 2015.

[14] J. L. Spinoso-Castillo, R. A. Chavez-Santoscoy, N. Bogdanchikova, J. A. Pérez-Sato, V. Morales-Ramos, and J. J. Bello-Bello, "Antimicrobial and hormetic effects of silver nanoparticles on in vitro regeneration of vanilla (Vanilla planifolia jacks. Ex Andrews) using a temporary immersion system," Plant Cell, Tissue and Organ Culture, vol. 129, no. 2, pp. 195-207, 2017.

[15] R. Vazquez-Muñoz, B. Borrego, K. Juárez-Moreno et al., “Toxicity of silver nanoparticles in biological systems: does the complexity of biological systems matter?," Toxicology Letters, vol. 276, pp. 11-20, 2017.

[16] N. Bogdanchikova, R. V. Muñoz, A. H. Saquero et al., "Silver nanoparticles composition for treatment of distemper in dogs," International Journal of Nanotechnology, vol. 13, no. $1 / 2 / 3$, pp. $227-237,2016$.

[17] B. Borrego, G. Lorenzo, J. D. Mota-Morales et al., "Potential application of silver nanoparticles to control the infectivity of Rift Valley fever virus in vitro and in vivo," Nanomedicine: Nanotechnology, Biology, and Medicine, vol. 12, no. 5, pp. 1185-1192, 2016.

[18] A. R. Ochoa-Meza, A. R. Álvarez-Sánchez, C. R. Romo-Quiñonez et al., "Silver nanoparticles enhance survival of white spot syndrome virus infected Penaeus vannamei shrimps by activation of its immunological system," Fish \& Shellfish Immunology, vol. 84, pp. 1083-1089, 2019.

[19] C. A. A. Hernández, K. Juarez-Moreno, M. E. CastañedaJuarez, A. P. HoracioAlmanza-Reyes, and N. Bogdanchikova, "Silver nanoparticles for the rapid healing of diabetic foot ulcers," International Journal of Medical Nano Research, vol. 4, no. 1, p. 019, 2017.

[20] K. Juarez-Moreno, E. B. Gonzalez, N. Girón-Vazquez et al., "Comparison of cytotoxicity and genotoxicity effects of silver nanoparticles on human cervix and breast cancer cell lines," Human \& Experimental Toxicology, vol. 36, no. 9, pp. 931948, 2017.

[21] W. W. Overwijk and N. P. Restifo, "B16 as a mouse model for human melanoma," Current Protocols in Immunology, vol. 39, no. 1, pp. 20.1.1-20.1.29, 2001.
[22] G. P. Otto, B. Rathkolb, M. A. Oestereicher et al., "Clinical chemistry reference intervals for C57BL/6J, C57BL/6N, and $\mathrm{C} 3 \mathrm{HeB} / \mathrm{FeJ}$ mice (Mus musculus)," Journal of the American Association for Laboratory Animal Science, vol. 55, no. 4, pp. 375-386, 2016.

[23] H. U. Aeschbacher, "Rates of micronuclei induction in different mouse strains," Mutation Research/Environmental Mutagenesis and Related Subjects, vol. 164, no. 2, pp. 109115, 1986.

[24] M. Laprise-Pelletier, T. Simão, and M. A. Fortin, "Gold nanoparticles in radiotherapy and recent progress in nanobrachytherapy," Advanced Healthcare Materials, vol. 7, no. 16, article 1701460, 2018.

[25] C. Núñez, S. V. Estévez, and M. del Pilar Chantada, "Inorganic nanoparticles in diagnosis and treatment of breast cancer," JBIC Journal of Biological Inorganic Chemistry, vol. 23, no. 3, pp. 331-345, 2018.

[26] P. Sivakumar, M. Lee, Y.-S. Kim, and M. S. Shim, "Photo-triggered antibacterial and anticancer activities of zinc oxide nanoparticles," Journal of Materials Chemistry B, vol. 6, no. 30, pp. 4852-4871, 2018.

[27] Y. Li, Y. Chang, X. Lian et al., "Silver nanoparticles for enhanced cancer theranostics: in vitro and in vivo perspectives," Journal of Biomedical Nanotechnology, vol. 14, no. 9, pp. 1515-1542, 2018.

[28] L. A. Austin, B. Kang, C.-W. Yen, and M. A. El-Sayed, "Plasmonic imaging of human oral cancer cell communities during programmed cell death by nuclear-targeting silver nanoparticles," Journal of the American Chemical Society, vol. 133, no. 44, pp. 17594-17597, 2011.

[29] M. J. Piao, K. A. Kang, I. K. Lee et al., "Silver nanoparticles induce oxidative cell damage in human liver cells through inhibition of reduced glutathione and induction of mitochondria-involved apoptosis," Toxicology Letters, vol. 201, no. 1, pp. 92-100, 2011.

[30] T. Verano-Braga, R. Miethling-Graff, K. Wojdyla et al., "Insights into the cellular response triggered by silver nanoparticles using quantitative proteomics," ACS Nano, vol. 8, no. 3, pp. 2161-2175, 2014.

[31] L. P. Franchi, B. B. Manshian, T. A. J. de Souza et al., "Cytoand genotoxic effects of metallic nanoparticles in untransformed human fibroblast," Toxicology In Vitro, vol. 29, no. 7, pp. 1319-1331, 2015.

[32] S. Kim and D. Y. Ryu, "Silver nanoparticle-induced oxidative stress, genotoxicity and apoptosis in cultured cells and animal tissues," Journal of Applied Toxicology, vol. 33, no. 2, pp. 7889, 2013.

[33] T. Shi, X. Sun, and Q. Y. He, "Cytotoxicity of silver nanoparticles against bacteria and tumor cells," Current Protein \& Peptide Science, vol. 19, no. 6, pp. 525-536, 2018.

[34] C. Carlson, S. M. Hussain, A. M. Schrand et al., "Unique cellular interaction of silver nanoparticles: size-dependent generation of reactive oxygen species," The Journal of Physical Chemistry B, vol. 112, no. 43, pp. 13608-13619, 2008.

[35] R. Foldbjerg, P. Olesen, M. Hougaard, D. A. Dang, H. J. Hoffmann, and H. Autrup, "PVP-coated silver nanoparticles and silver ions induce reactive oxygen species, apoptosis and necrosis in THP-1 monocytes," Toxicology Letters, vol. 190, no. 2, pp. 156-162, 2009.

[36] D. Guo, L. Zhu, Z. Huang et al., "Anti-leukemia activity of PVP-coated silver nanoparticles via generation of reactive 
oxygen species and release of silver ions," Biomaterials, vol. 34, no. 32, pp. 7884-7894, 2013.

[37] A. Avalos, A. I. Haza, D. Mateo, and P. Morales, "Interactions of manufactured silver nanoparticles of different sizes with normal human dermal fibroblasts," International Wound Journal, vol. 13, no. 1, pp. 101-109, 2016.

[38] G. Joksić, J. Stašić, J. Filipović, A. V. Šobot, and M. Trtica, "Size of silver nanoparticles determines proliferation ability of human circulating lymphocytes in vitro," Toxicology Letters, vol. 247, pp. 29-34, 2016.

[39] W. Liu, Y. Wu, C. Wang et al., "Impact of silver nanoparticles on human cells: effect of particle size," Nanotoxicology, vol. 4, no. 3, pp. 319-330, 2010.

[40] H. J. Wang, L. Yang, H. Y. Yang et al., “Antineoplastic activities of protein-conjugated silver sulfide nano-crystals with different shapes," Journal of Inorganic Biochemistry, vol. 104, no. 1, pp. 87-91, 2010.

[41] T. Bartłomiejczyk, A. Lankoff, M. Kruszewski, and I. Szumiel, "Silver nanoparticles-allies or adversaries?," Annals of Agricultural and Environmental Medicine, vol. 20, no. 1, pp. 4854, 2013.

[42] G. Vecchio, M. Fenech, P. P. Pompa, and N. H. Voelcker, "Lab-on-a-Chip-based high-throughput screening of the genotoxicity of engineered nanomaterials," Small, vol. 10, no. 13, pp. 2721-2734, 2014.

[43] A. M. J. Fichtinger-Schepman, S. D. van der Velde-Visser, H. C. M. van Dijk-Knijnenburg, A. T. van Oosterom, R. A. Baan, and F. Berends, "Kinetics of the formation and removal of cisplatin-DNA adducts in blood cells and tumor tissue of cancer patients receiving chemotherapy: comparison with in vitro adduct formation," Cancer Research, vol. 50, no. 24, pp. 7887-7894, 1990.

[44] R. Alemón-Medina, M. E. Bravo-Gómez, M. I. Gracia-Mora, and L. Ruiz-Azuara, "Comparison between the Antiproliferative effect and intracellular glutathione depletion induced by Casiopeína IIgly and cisplatin in murine melanoma B16 cells," Toxicology In Vitro, vol. 25, no. 4, pp. 868-873, 2011.

[45] Y. M. Choi, H.-K. Kim, W. Shim et al., "Mechanism of cisplatin-induced cytotoxicity is correlated to impaired metabolism due to mitochondrial ROS generation," PLoS One, vol. 10, no. 8, article e0135083, 2015.

[46] X. Guo, C. Jagannath, M. G. Espitia, and X. Zhou, "Uptake and silica and carbon nanotubes by human macrophages/monocytes induces activation of fibroblasts in vitro - potential implication for pathogenesis of inflammation and fibrotic diseases," International Journal of Immunopathology and Pharmacology, vol. 25, no. 3, pp. 713-719, 2012.

[47] J. Lin, Z. Huang, H. Wu et al., "Inhibition of autophagy enhances the anticancer activity of silver nanoparticles," Autophagy, vol. 10, no. 11, pp. 2006-2020, 2014.

[48] K. Kang, D. H. Lim, I. H. Choi et al., "Vascular tube formation and angiogenesis induced by polyvinylpyrrolidone-coated silver nanoparticles," Toxicology Letters, vol. 205, no. 3, pp. 227-234, 2011.

[49] R. Limade, A. B. Seabra, and N. Durán, "Silver nanoparticles: a brief review of cytotoxicity and genotoxicity of chemically and biogenically synthesized nanoparticles," Journal of Applied Toxicology, vol. 32, no. 11, pp. 867-879, 2012.

[50] B. J. S. Sanderson, L. R. Ferguson, and W. A. Denny, "Mutagenic and carcinogenic properties of platinum-based anticancer drugs," Mutation Research/Fundamental and
Molecular Mechanisms of Mutagenesis, vol. 355, no. 1-2, pp. 59-70, 1996.

[51] S. Castro-Gamboa, M. R. Garcia-Garcia, G. Piñon-Zarate et al., "Toxicity of silver nanoparticles in mouse bone marrowderived dendritic cells: implications for phenotype," Journal of Immunotoxicology, vol. 16, no. 1, pp. 1-9, 2019.

[52] A. A. Shumakova, V. A. Shipelin, Y. S. Sidorova et al., “Toxicological evaluation of nanosized colloidal silver, stabilized with polyvinylpyrrolidone. I. Characterization of nanomaterial, integral, hematological parameters, level of thiol compounds and liver cell apoptosis," Voprosy Pitaniia, vol. 6, pp. 46-57, 2015.

[53] E.-A. Jun, K.-M. Lim, K. Y. Kim et al., "Silver nanoparticles enhance thrombus formation through increased platelet aggregation and procoagulant activity," Nanotoxicology, vol. 5, no. 2, pp. 157-167, 2011.

[54] D. N. Seril, J. Liao, C. S. Yang, and G. Y. Yang, "Systemic iron supplementation replenishes iron stores without enhancing colon carcinogenesis in murine models of ulcerative colitis: comparison with iron-enriched diet," Digestive Diseases and Sciences, vol. 50, no. 4, pp. 696-707, 2005.

[55] N. Kaushal, S. Hegde, J. Lumadue, R. F. Paulson, and K. S. Prabhu, "The regulation of erythropoiesis by selenium in mice," Antioxidants \& Redox Signaling, vol. 14, no. 8, pp. 1403-1412, 2011.

[56] P. Matak, S. Zumerle, M. Mastrogiannaki et al., "Copper deficiency leads to anemia, duodenal hypoxia, upregulation of HIF- $2 \alpha$ and altered expression of iron absorption genes in mice," PLoS One, vol. 8, no. 3, article e59538, 2013. 


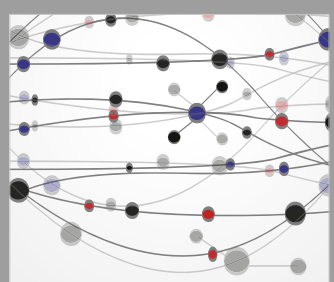

The Scientific World Journal
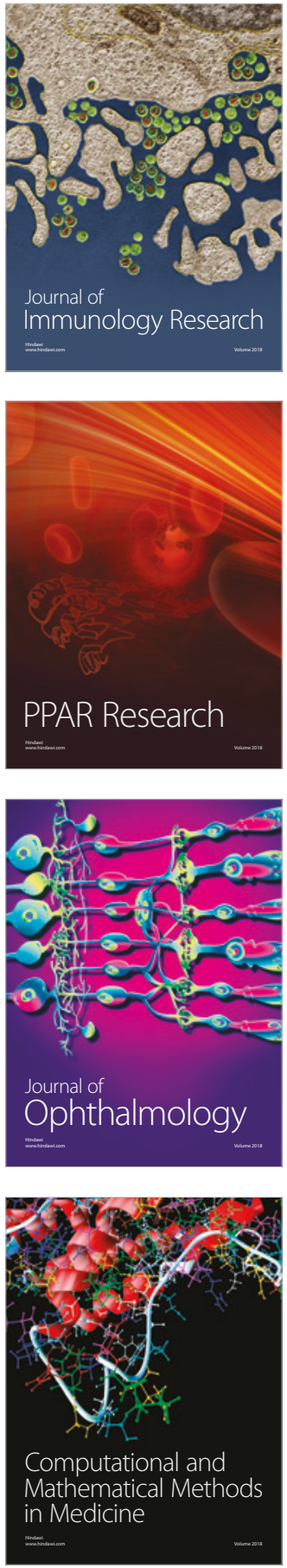

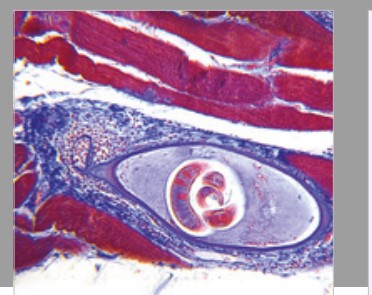

Gastroenterology Research and Practice

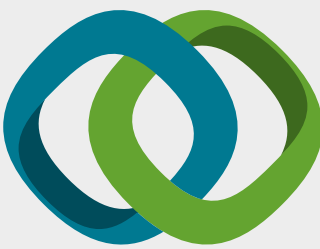

\section{Hindawi}

Submit your manuscripts at

www.hindawi.com
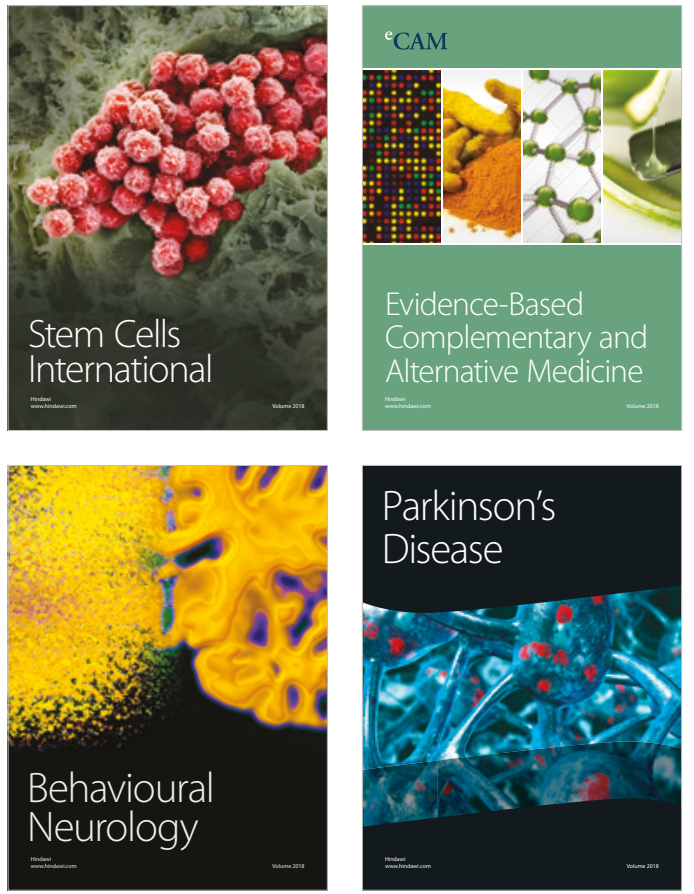

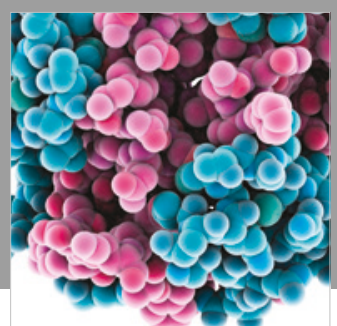

ournal of

Diabetes Research

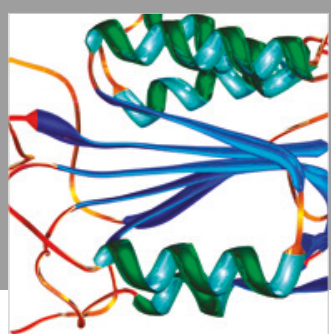

Disease Markers
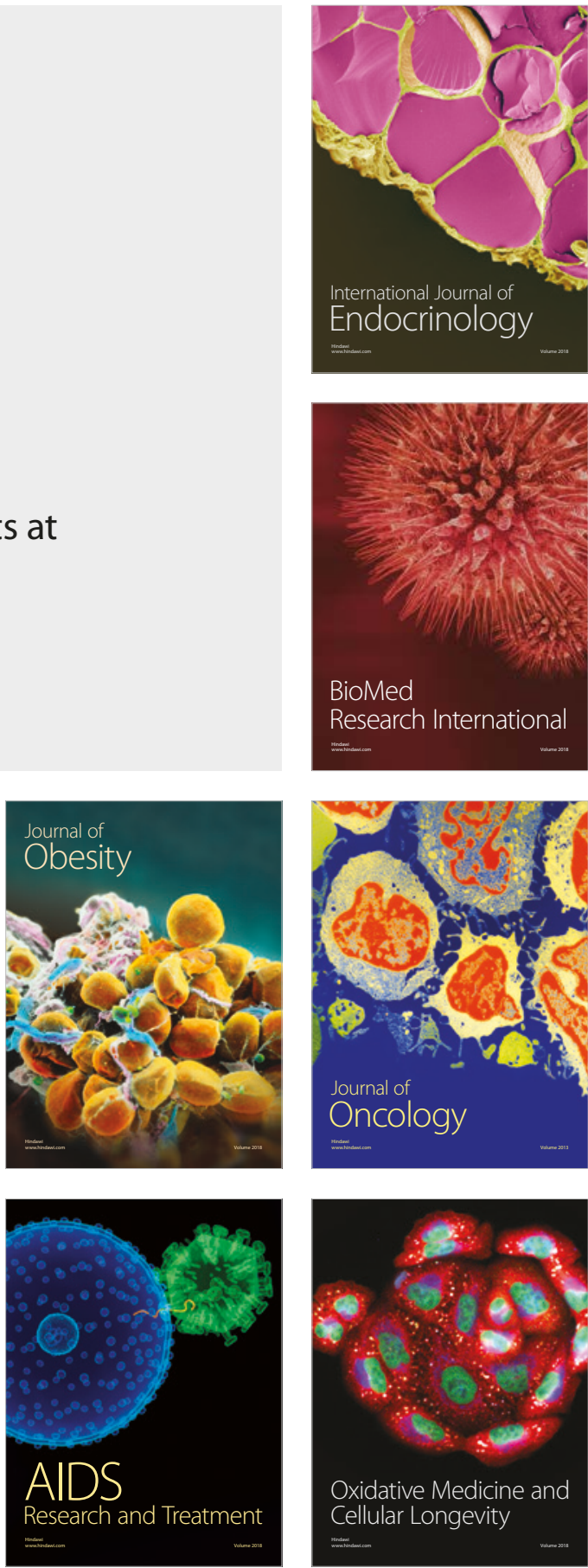